\title{
Sliding mode observer and controller for Performance improvement of Brushless DC Motor
}

\author{
Devendra Potnuru $^{\# 1}$, Y.Santosh Kumar *2 \\ \# Associate Professor, EEE department, GMRIT, Srikakulam, A.P., India \\ 1 devendra.p@gmail.com \\ * M.Tech student, EEE department, GMRIT, Srikakulam, A.P., India \\ 2 yadlapalli.santoshkumar@gmail.com
}

\begin{abstract}
The present paper proposes a control scheme comprising of a new sliding mode controller (SMC) with sliding mode observer (SMO) for improved performance of a Brushless DC (BLDC) motor. The SMO is used to estimate rotor speed and rotor position using terminal voltages and currents of the BLDC motor. The error between actual and estimated currents taken as the sliding surface from which the back emf is estimated which is further used to estimate rotor position and speed. The SMC consists of both speed control and current control loops where the reference to the currents is derived from speed error using PI controller. The speed error and current error together comprises the sliding surface. The proposed SMC is an alternative to second order SMC and it eliminates the derivative of the sliding variable for speed control thus eliminating complexity while preserving the benefits. The simulation results of the proposed scheme are compared with those of the conventional scheme to prove its effectiveness.
\end{abstract}

Keyword-BLDC Motor, Sliding mode controller, Sliding mode observer

\section{INTRODUCTION}

There has been a tremendous interest in permanent magnet drives in recent years due to their excellent characteristics like low power requirement, high energy savings and ease of control. Majority of the BLDC motor advantages attributed to its construction in which its armature winding placed in stator and field is provided withthe permanent magnets placed in rotor. This makes the cooling arrangement is easier for BLDC motor as compared to the conventional dc motor. Due to the permanent magnet rotor, the commutation process is not possible from the rotor side like a DC motor [1]. So an electronic commutation is used in which the supply to the motor will be controlled through inverter. In order to make a phase to conduct, we need to find the exact location of the rotor poles and the commutation sequence must be ensured such that a phase difference of 90o must be maintained between stator flux and rotor flux to get maximum torque [2].

To attain information regarding the position of rotor, transducers like hall sensors are used. The hall sensor transmits logic high or logic low signal based on the proximity of a pole as the magnetic field of a pole induces emf in it. For a three phase BLDC motor, three sensors are aligned with 1200 phase shift to get complete information regarding back emf voltages in all phases and this hall sensor circuit is placed on the non-rotating part of motor [3].

The position sensor circuit requires a special arrangement to be mounted on the motor and need dedicated electronic circuitry. If the motor is far away from the control center, then we need a separate cabling system for signal transmission. All these requirements increase the cost and reduce the reliability of the drive [4]. Hence sensor control schemes cannot be utilized in situations where high reliability is needed and the motor has to operate in harsh environments. One of the solutions is to estimate the position of the rotor using voltage and current measurements. Since we are eliminating the need of position sensors, it can be treated as sensorless control. Sensorless control can also be utilized as a backup scheme where hall sensors are already in use. For rotor position estimation, sensorless algorithms depend on measured values of motor currents and motor terminal voltages. In many of the sensorless methods, position and speed information is estimated using back emf voltages. This back emf estimated either by direct or indirect methods. Further, in direct back emf sensing zero crossing detection of the back emf using voltage dividers is utilized. The principle of this method is that whenever two of the three phases are conducting, the remaining phase will carry only the back emf which can be used for position sensing. But it contains high frequency noise so low pass filters are essential in reducing harmonics. But the filter introduces delay and reduces sensitivity. The zero crossing of the back emf does not represent the commutation periods and it should be ensured that there will be a phase shift in signals used for commutation. These limitations can be eliminated with the indirect back emf sensing methods such as voltage integration method or terminal current sensing method [4]. 
Sensorless methods are further diversified into the open loop and closed loop methods. In open loop sensorless methods, the rotor position obtained directly from sensing of terminal voltages without any correction mechanism so these methods are sensitive to parameter variations. In close loop methods, observer schemes that use internal correction mechanism are implemented. Observers are again classified into full order and reduced order models. Full order observers can estimate the states based measurements of all the states but the reduced order observer is based measurements of some of the states. Reduced order observers may be a flux observer or a current observer. In the flux observer the reference model is a magnetic model and inthe reduced order current observer it is the electrical model from which rotor position is attained by estimating the back emf voltages [5].

SMO is a reduced order current observer which usesthe terminal voltages and currents of BLDC motor to estimate the rotor speed and rotor position [6]. Several methods are implemented in the SMO technique for better results. A hybrid SMO proposed in [7] is used for the speed and rotor position estimation in the multiple reference frame (MRF). Another SMO scheme presented in [8] estimates the back emf from which the Zero Crossing Detectors estimate commutation points. The proposed scheme made an effort to reduce the number of gains to be selected properly to ensure the convergence of both states. A new method to sense the rotor position and speed for PMSM based on SMO is presented [9] in which the signum function is replaced with a saturation function and calculation of differential speed is substituted with a phase locked loop (PLL) and a low-pass filter with variable cut-off frequency is used for improved filtering. The paper [10] implemented an Iterative SMO which improves the motor speed and angle estimation by reducing the estimation error in the back emf by iteratively using the observer and this scheme used a sigmoid function as the switching functionto reduce chattering. The paper [6] represented a modified SMO in which the speed component is added in the back emf estimation which minimised the phase shift at higher speeds and multiple zero at lower speeds.

In the proposed scheme phase currents are estimated within the SMO and then compared with actual currents. The error between actual and the estimated currents constitutes the sliding surface. A saturation function is used as switching function to reduce chattering. Integration of the switching function provides the back emf estimation. Rotor speed is calculated using estimated back emfs and integration of speed provides rotor position. A BLDC motor as a variable speed drive has features like ease of control and low maintenance. For faster and accurate control, current controlled voltage source inverters are preferred. The conventional PI controller and hysteresis controller are simple techniques for the speed control of the BLDC motor. But for higher order circuits like this motor these techniques result in poor performance [11].

The SMC approach is a most suitable scheme to deal with these types of systems under uncertain conditions as it delivers better performance in terms of simple and robust control. On the otherhand SMC suffers with the undesirable phenomenon of oscillations called chattering effect as also its control action is discontinuous in nature and it ideally operates at infinite switching frequency. It is mainly due to the use of signum function in the sliding surface. It is responsible for less accurate control and high stress in the power circuits. Chattering can be minimised by using a continuous function to smoothen the switching term before the sliding variable reaches the sliding phase. It can also be reduced by using SMC with carrier-based fixed switching frequency method with proper design of the parameters [12].

There are many approaches in the field of SMC. The paper [13] proposed a second order SMC algorithm which requires only the actual motor parameter information and does not need any current feedback. An adaptive fuzzy SMC strategy was developed in the paper [14], in which the control law of the controller is governed by the control algorithm depending on the output of the SMC to minimise uncertain delay in the network control system. A hybrid method of SMC scheme consists of a non-singular terminal sliding mode method and the high-order sliding-mode method in [15]. A cascade SMC with PID controller is developed in [16] based on an integral control which uses the concept of weight function and error window concept.The paper [17] gives a new two-degree-of-freedom PID controller structure based on Takagi-Sugeno fuzzy controller for speed and position control of BLDC drives. A second order SMC with anti-windup for BLDC motor is proposed in [18] in which the speed control is based on the super twisting algorithm based on the dq field oriented frame model. A dual loop control strategy implemented in [19] in which a SMC for speed control and a SMO for torque estimation are designed. The paper [20] proposes a SMC with unidirectional auxiliary surfaces to deal with indefinite friction forces and inertia. A cascade SMC method is implemented in [21] for the closed loop control of torque and speed based on the first order SMC and Super-Twisting algorithm respectively. A control methodology of SMC is proposed in [22] in which the SMC is used in the inner control loop and PI controller is used in the outer control loop to minimise the steady-state error.

The drive controller comprises of an outer speed control loop and an inner current control loop. The reference of the inverter phase current in the current control loop is derived from the speed error using a PI controller. The stability of the system will be improved as the steady state error can be minimised by the PI controller and sliding mode is used in the inner current control loop. The speed error and the current error together comprise the sliding surface. The saturation function is used as a switching function based on which the proper switching sequence of the inverter can be attained. 
In this paper, firstly based on the modeling equations of BLDC motor, SMO is designed to estimate the rotor position and speed. Then SMC is implemented to control the inverter for the optimum performance of the motor. The model is simulated using MATLAB/SIMULINK and the simulation results have been presented. To prove its effectiveness, thsese results are compared with those of the conventional control scheme of hysteresis current controller with SMO.

\section{SLiding Mode ObSERVER AND CONTROLler}

In this presented approach, the observer and the controller are designed based on the dynamic model of BLDC motor and their details are given in the following sections

\section{A. Sliding Mode Observer}

In SMO, the reference currents taken from the motor model and the adaptive model produce the estimated motor currents. The error between estimated and actual currents is fed back to adaptive model to estimate the back emf [5]. The sliding mode observer equations for the current and back emf estimation for the phase-A is proposed as,

$$
\begin{aligned}
& \frac{d \hat{i}_{a}}{d t}=\frac{1}{L} V_{a}-\frac{R_{s}}{L} \hat{i}_{a}-\frac{1}{L} \hat{e}_{a}+a_{1} \operatorname{sat}\left(s_{\boldsymbol{\sigma}}\right) \\
& \frac{d \hat{e}_{a}}{d t}=a_{2} \operatorname{sat}\left(s_{\boldsymbol{\sigma}}\right)
\end{aligned}
$$

Where $\hat{i}_{a}, \hat{e}_{a}$ are the estimated values of phase current and back emf respectively and $s_{\sigma}$ is the sliding surface which is the error between actual and estimated currents. The chattering effect eliminated with the use of the saturation function which is defined as,

$$
\operatorname{sat}\left(s_{\sigma}\right)=\left\{\begin{array}{cl}
\frac{\left|s_{\sigma}\right|}{\varepsilon} ; & \left|s_{\sigma}\right| \leq \varepsilon \\
\operatorname{sign}\left(s_{\sigma}\right) ; & \left|s_{\sigma}\right|>\varepsilon
\end{array}\right.
$$

Where $\boldsymbol{\varepsilon}$ is the sliding surface band.

The sliding surface reaches to zero when both actual and estimated currents converge. To ensure convergence, observer gains a1 and a2 must be selected properly. An estimation algorithm based on sliding mode with a combination of a stability theorem ensures stability and convergence of estimation.

The observer gain values can be chosen such that,

$a_{1}>\frac{1}{L}|e|_{\max } \quad$ and $\quad a_{2}<0$

Where $|e|_{\max }$ is the maximum value of phase back emf.

For simplicity, consider the absolute value of current observer gain $a_{1}$ as,

$a_{1}=\frac{1}{L}|e|_{\max }$

The value of back emf observer gain is proportional to the ratio of actual speed $\mathrm{N}$ to maximum speed Nmax is multiplied with the back emf observer gain as,

$a_{2}=-\gamma \cdot\left(\frac{1}{L}|e|_{\max }\right) \cdot\left(\frac{N}{N_{\max }}\right)$

Where $\gamma$ is a constant.

The maximum value of phase back emf can be resented as

$$
e_{\max }=k_{b} \cdot \omega_{m}=k_{b}\left(\frac{2 \pi \cdot N}{60}\right)
$$

Where $\mathrm{kb}$ is the back emf constant and $\omega_{m}$ is rotor speed. 
After inserting (12) and constants in both (10) and (11) these equations transformed as,

$$
\begin{aligned}
& a_{1}=420.327 \cdot\left(\frac{2 \pi \cdot N}{60}\right) \\
& a_{2}=-456.854 \cdot\left(\frac{2 \pi \cdot N}{60}\right) \cdot\left(\frac{N}{4000}\right)
\end{aligned}
$$

The rotor speed is estimated with the help of back emf voltages as,

$$
\hat{\omega}_{m}=\frac{1}{k_{b}} \sqrt{\hat{e}_{a}^{2}+\hat{e}_{b}^{2}+\hat{e}_{c}^{2}}
$$

Where $\hat{\omega}_{m}$ is the estimated value of rotor electrical speed.

The rotor position $\hat{\theta}_{r}$ is calculated with the estimated rotor speed as,

$$
\frac{d \hat{\theta}_{r}}{d t}=\frac{p}{2} \hat{\omega}_{m}
$$

Where $\mathrm{p}$ is the number of poles.

\section{B. Sliding Mode controller}

The proposed controller is a modified version of the second order sliding mode controller. For speed control of BLDC motor, the sliding surface $s_{\boldsymbol{\alpha}}$ of a second order sliding mode control is given as,

$s_{\boldsymbol{\alpha}}=\frac{d \omega_{e}}{d t}+\omega_{e}$

Where $\omega_{e}$ is the error in the rotor speed which can be represented as,

$\omega_{e}=\omega_{r e f}-\omega$

Where $\omega_{\text {ref }}$ reference is speed and $\omega$ is actual speed.

From the electromagnetic torque equation, the state equation of rotor speed is obtained as,

$\frac{d \omega_{m}}{d t}=\frac{\left(T_{e}-T_{l}\right)}{J}-\frac{B}{J} \omega_{m}$

From (14) the derivative of speed error is given as,

$\frac{d \omega_{e}}{d t}=\frac{1}{J}\left(T_{e-r e f}-T_{e}\right)-\frac{B}{J}\left(\omega_{r e f}-\omega\right)$

Where $T_{e-r e f}$ is the reference electromagnetic torque which can be derived from speed error using PI controller as,

$$
T_{e-r e f}=\left(k_{p}+\frac{k_{i}}{s}\right) \cdot\left(\omega_{r e f}-\omega\right)
$$

As electromagnetic torque and current are related as,

$T_{e}=k_{t} \cdot i$

Where $i$ the phase is current, $k_{t}$ is the torque constant. Equation (16) can be modified as,

$i_{r e f}=\frac{1}{k_{t}}\left(k_{p}+\frac{k_{i}}{s}\right) \cdot\left(\omega_{r e f}-\omega\right)$

Where $i_{\text {ref }}$ is the reference current. 
After substituting (21) and (22) in (19),

$\frac{d \omega_{e}}{d t}=\frac{k_{t}}{J}\left(i_{r e f}-i\right)-\frac{B}{J}\left(\omega_{r e f}-\omega\right)$

The sliding surface can be modified by inserting (23) in (17) as,

$s_{\boldsymbol{\alpha}}=\frac{k_{t}}{J}\left(i_{r e f}-i\right)+\left(1-\frac{B}{J}\right)\left(\omega_{r e f}-\omega\right)$

Where $\omega_{e}=\omega_{\text {ref }}-\omega$ the error in the rotor is speed and $i_{e}=i_{r e f}-i$ is the error in the current.

The proposed sliding surface can be redefined as,

$s_{\boldsymbol{\alpha}}=b_{1}\left(i_{r e f}-i\right)+b_{2}\left(\omega_{r e f}-\omega\right)$

Once the sliding surface $s_{\alpha}$ is calculated, the control input to the inverter is selected with reference to switching function as,

$\begin{array}{llll}u & =+1 ; V_{0}=+V_{d c} & \text { for } & s_{\boldsymbol{\alpha}}>0 \\ u=-1 ; V_{0}=-V_{d c} & \text { for } & s_{\boldsymbol{\alpha}}<0\end{array}$

\section{III.RESULT ANALYSIS AND DISCUSSIONS}

The proposed scheme of sensorless control of the BLDC motor using SMO and SMC are simulated using MATLAB/SIMULINK using the motor parameters listed in the Table. 1.

\section{A. Rotor position and speed estimation}

The position and speed estimated with SMO is compared with that of actual values to check the accuracy of the SMO. Figure 1 represents actual and estimated rotor position and rotor speed using SMO and SMC at 3000 $\mathrm{r} / \mathrm{min}$.

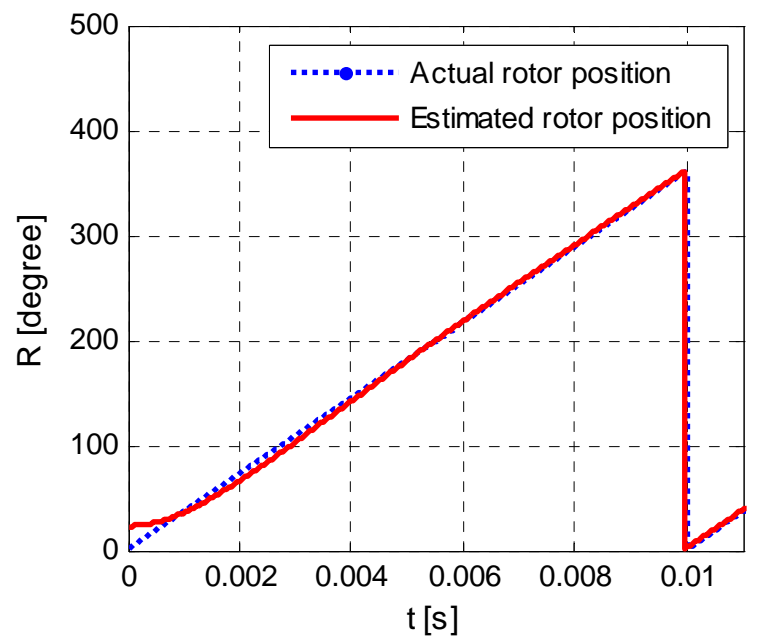

(a)

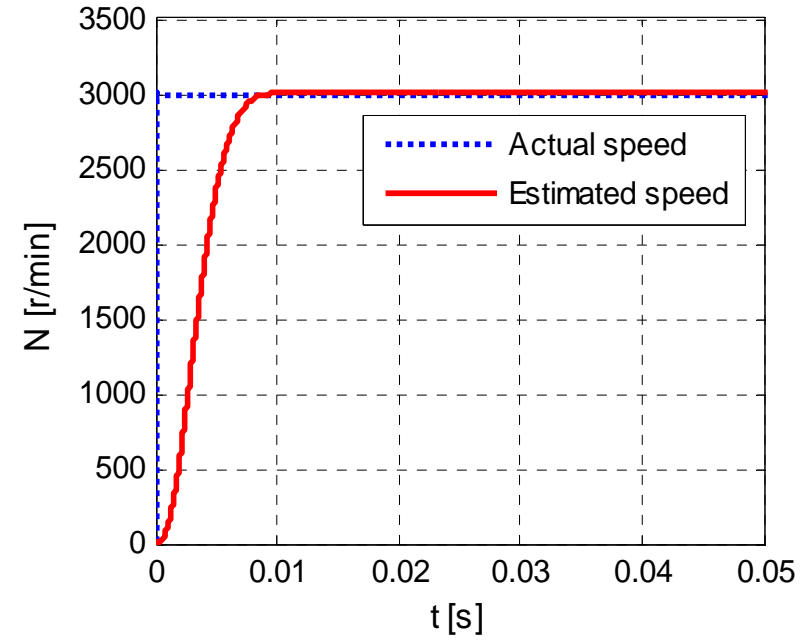

(b)

Figure1. Actual and estimated parameters using a sliding mode observer and controller at $3000 \mathrm{r} / \mathrm{min}$ : (a) rotor position $\mathrm{R}$ versus time $\mathrm{t}$, (b) rotor speed $\mathrm{N}$ versus time.

From Figure 1, it is observed that the estimated rotor position has an error of 20 with respect to the actual rotor position and estimated speed has an error of $0.5 \mathrm{r} / \mathrm{min}$ from actual speed.

B. Speed and torque performance

To assess the effectiveness of the proposed controller, a hysteresis current controller scheme is used for comparison. The simulation models run at different speeds such as $500 \mathrm{r} / \mathrm{min}, 1500 \mathrm{r} / \mathrm{min}$ and $3000 \mathrm{r} / \mathrm{min}$ with a load 0.5 N.m applied at $3 \mathrm{~s}$. When the proposed scheme is simulated at $500 \mathrm{r} / \mathrm{min}$, the speed characterstics are shown in Figure.2. But their torque curves as shown in Figure 3 exposes that torque ripple is well minimized to 0.0005 N.m in the proposed controller while in case of a hysteresis controller, it is 0.001 N.m. 


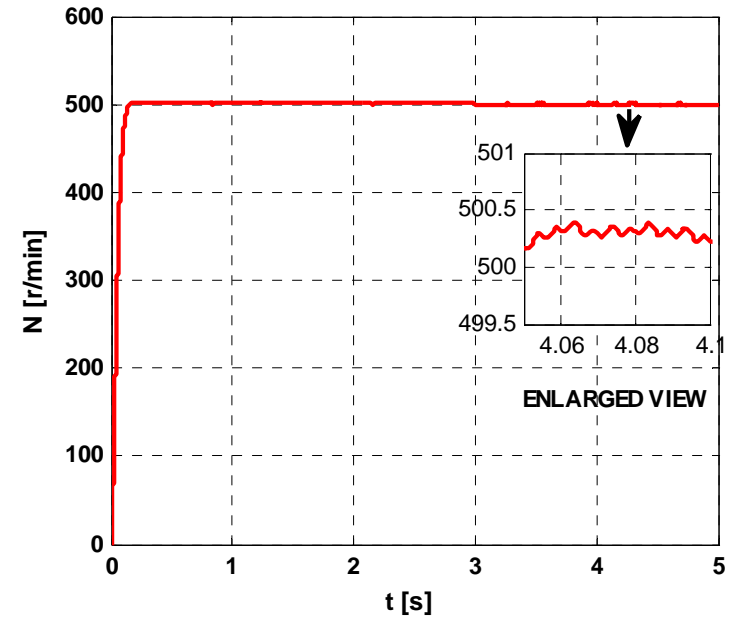

(a)

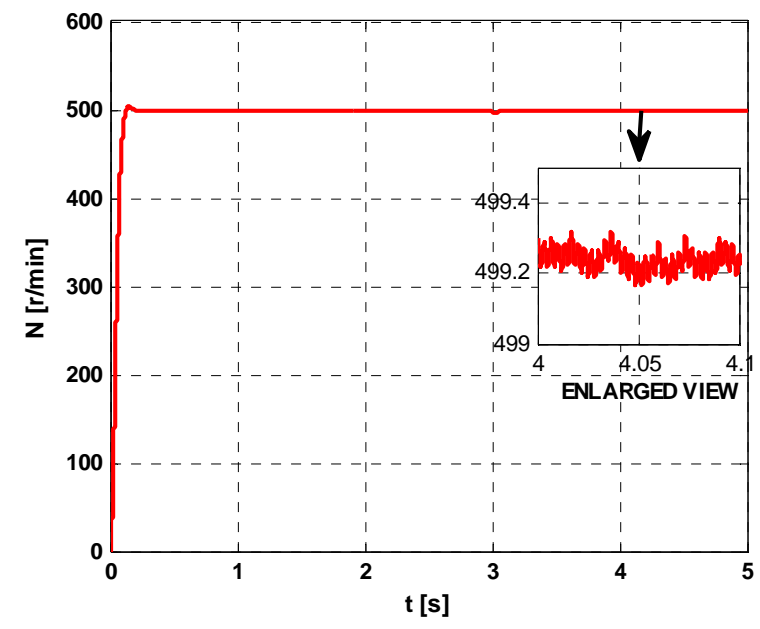

(b)

Figure 2. Speed N versus time (Sec) curve at $500 \mathrm{r} / \mathrm{min}$ : (a) with sliding mode observer and hysteresis controller, (b) with sliding mode observer and controller.

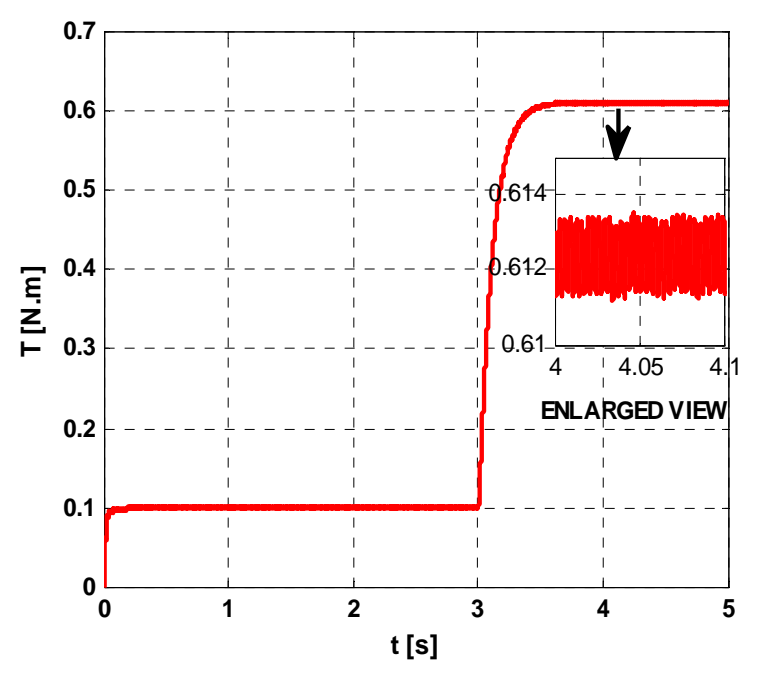

(a)

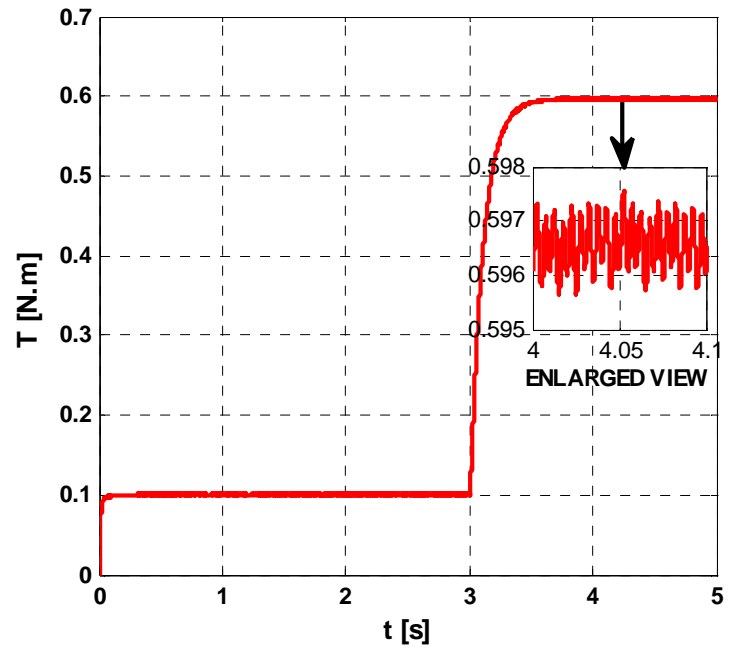

(b)

Figure 3. Electromagnetic torque T versus time (t) curve at $500 \mathrm{r} / \mathrm{min}$ : (a) with sliding mode observer and hysteresis controller, (b) With sliding mode and controller.

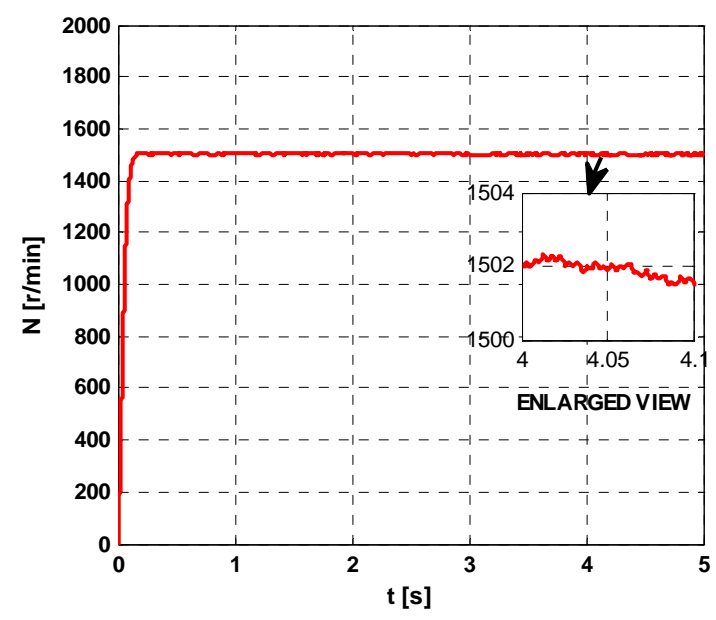

(a)

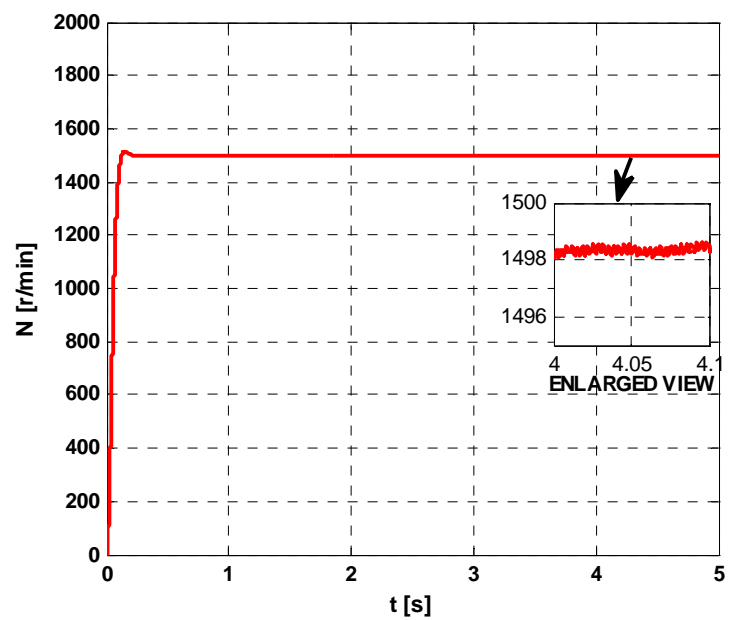

(b)

Figure 4. Speed N versus time (sec) curve at $1500 \mathrm{r} / \mathrm{min}$ : (a) with sliding mode observer and hysteresis controller, (b) with sliding mode observer and controller. 


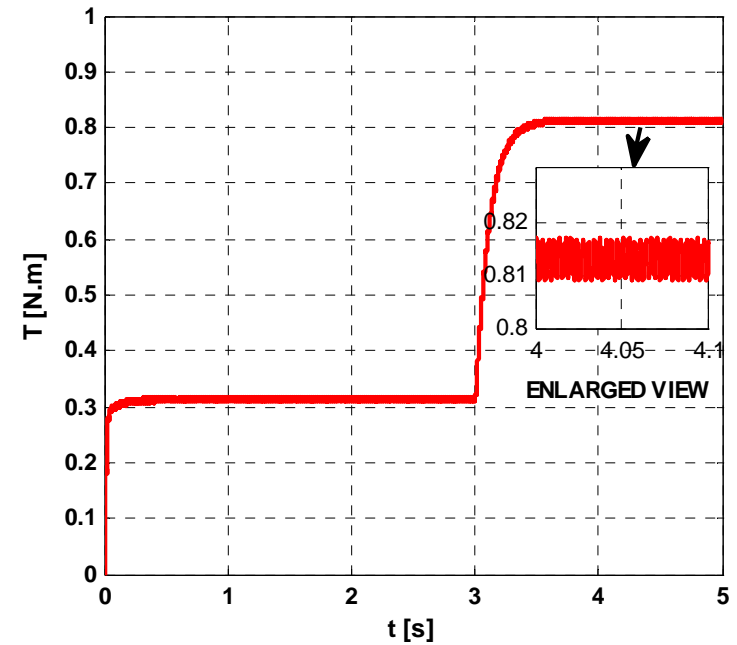

(a)

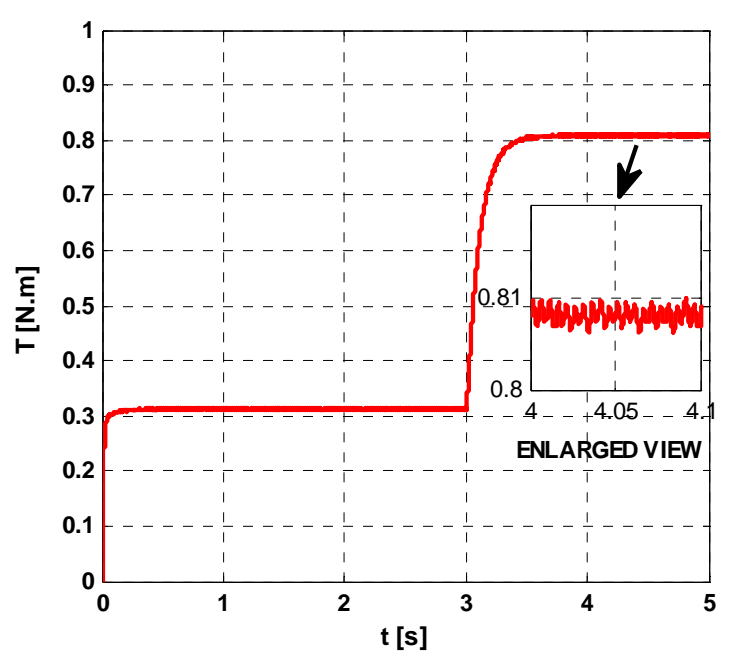

(b)

Figure 5. Electromagnetic torque $\mathrm{T}$ versus time $\mathrm{t}$ curve at $1500 \mathrm{r} / \mathrm{min}$ : (a) with sliding mode observer and hysteresis controller, (b) with sliding mode observer and controller.

When the proposed scheme is run at $1500 \mathrm{r} / \mathrm{min}$, speed characteristics are much similar with an accuracy of 0.5 $\mathrm{r} / \mathrm{min}$ in both controllers as shown in Figure 4 but their torque curves as shown in Figure 5 depicts that the torque ripple is $0.001 \mathrm{~N} . \mathrm{m}$ using the proposed controller and it is $0.003 \mathrm{~N} . \mathrm{m}$ using hysteresis controller. When both models are simulated at $3000 \mathrm{r} / \mathrm{min}$, the corresponding speed curves are shown in Figure 6 and their torque curves as shown in Figure 7 and it is evident that the ripple in the torque is 0.003 N.m in case of SMC and it is 0.006 N.m with hysteresis controller.

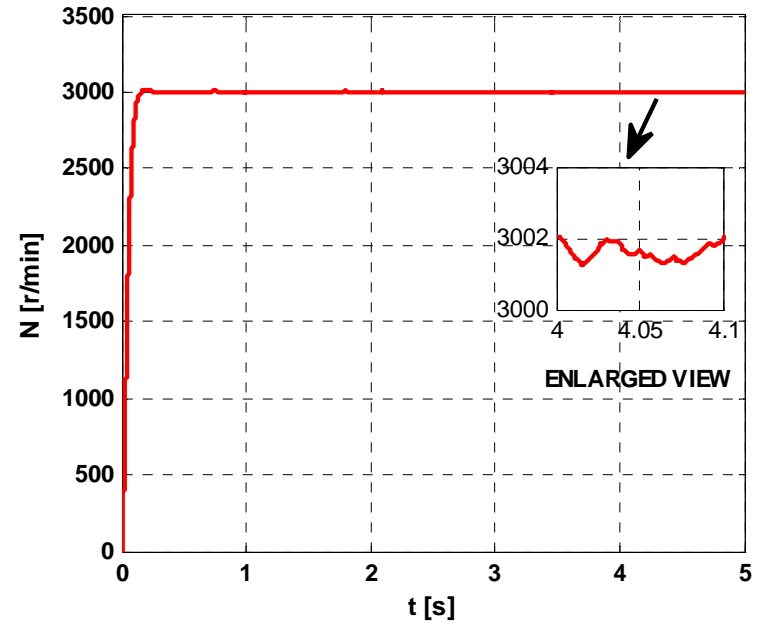

(a)

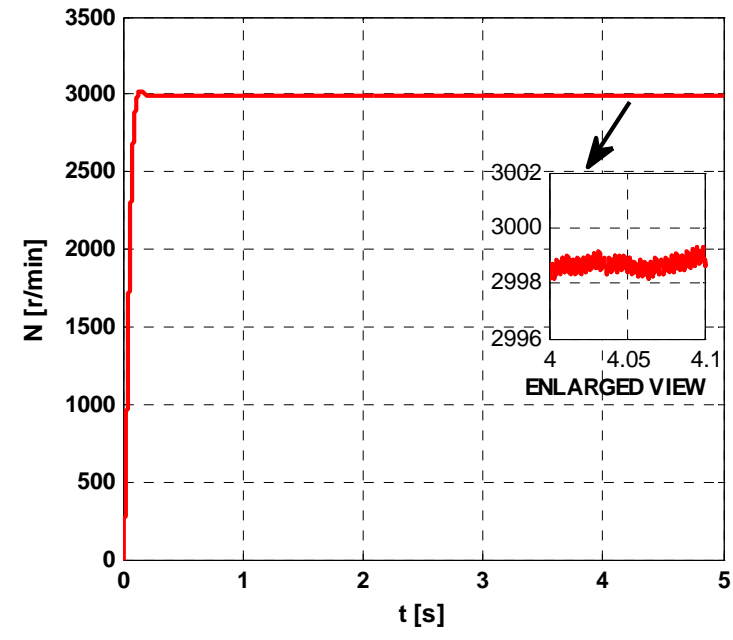

(b)

Figure.6. Speed N versus time (sec) curve at $3000 \mathrm{r} / \mathrm{min}$ : (a) with a sliding mode observer and hysteresis controller, (b) with sliding mode observer and controller. 


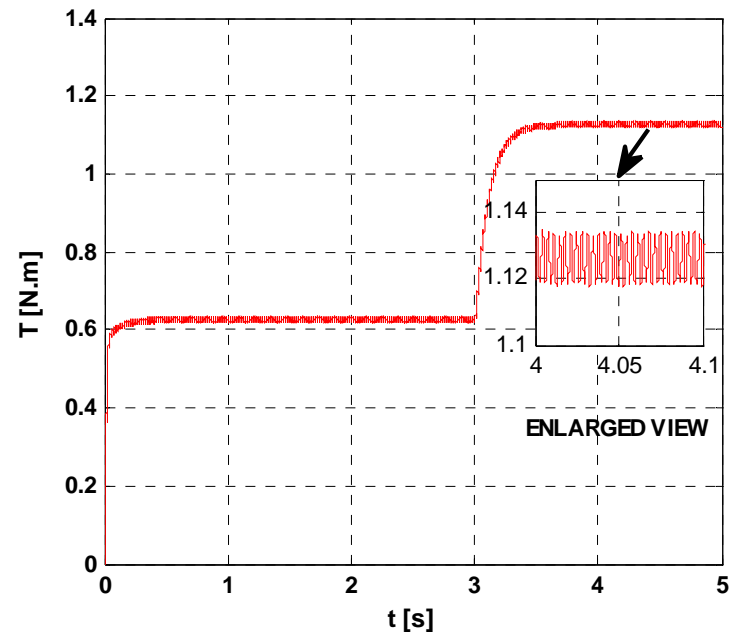

(a)

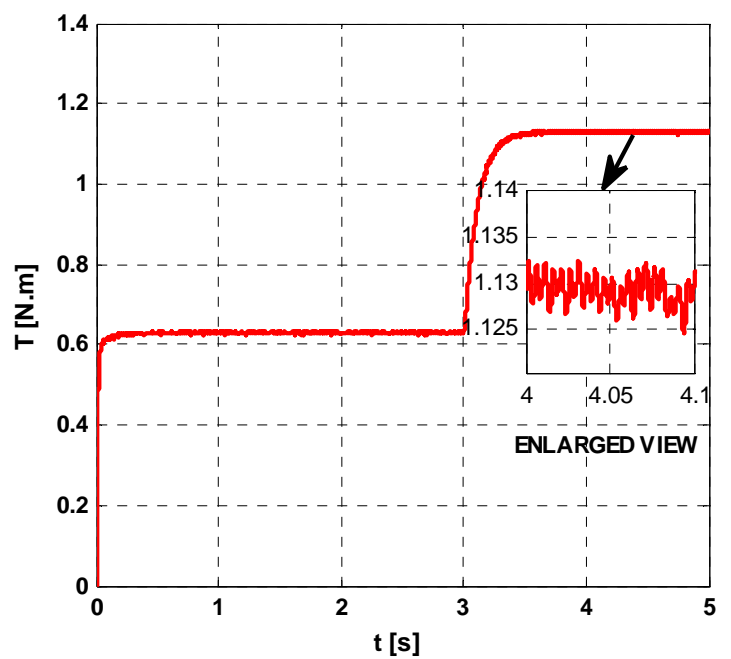

(b)

Figure.7. Electromagnetic torque T versus time curve at $3000 \mathrm{r} / \mathrm{min}$ : (a) with sliding mode observer and hysteresis controller, (b) with sliding mode observer and controller.

TABLE I. BLDC MOTOR PARAMETERS

\begin{tabular}{|l|l|l|l|}
\hline Parameter name & Symbol & Value & Unit \\
\hline Poles & $\mathrm{P}$ & 4 & --- \\
\hline Stator resistance & $\mathrm{Rs}$ & 0.75 & $\Omega$ \\
\hline Stator self-inductance & $\mathrm{Ls}$ & 1.75 & $\mathrm{mH}$ \\
\hline Mutual inductance & $\mathrm{M}$ & 1.6 & $\mathrm{mH}$ \\
\hline Back emf constant & $\mathrm{kb}$ & 0.56 & $\mathrm{~V} / \mathrm{rad} / \mathrm{sec}$ \\
\hline Torque constant & $\mathrm{kt}$ & 0.055 & $\mathrm{Nm} / \mathrm{A}$ \\
\hline Moment of inertia & $\mathrm{J}$ & 0.00027 & $\mathrm{Kg} \cdot \mathrm{m} / \mathrm{s} 2$ \\
\hline Friction coefficient & $\mathrm{B}$ & 0.00198 & $\mathrm{~N} \cdot \mathrm{m} / \mathrm{rad} / \mathrm{sec}$ \\
\hline DC voltage & $\mathrm{Vdc}$ & 160 & $\mathrm{~V}$ \\
\hline Maximum speed & $\mathrm{N}$ & 4000 & $\mathrm{r} / \mathrm{min}$ \\
\hline
\end{tabular}

\section{IV.CONCLUSION}

This paper a closed loop control scheme of BLDC motor using SMC in conjunction with SMO is proposed. The SMO is designed to estimate the rotor position and rotor speed to eliminate the necessity of sensors. To check the accuracy of the observer, estimated speed and rotor position are compared with the actual parameters of BLDC motor and both are identical. The new SMC is implementedwhich is an alternative to the second order SMC and it eliminates the derivative of the sliding variable for speed control. The proposed controller is compared with the conventional hysteresis current controller and it is proven that the proposed scheme exhibits more accurate and faster response in performance improvement of BLDC motor without the need of any position sensors.

\section{REFERENCES}

[1] Saswathi Swapna Das ,Byamakesh Nayak, Subrath Kumar,Feedback control and Dynamic behavior of Z-source converter fed separately excited DC motor and centrifugal pump set, International Journal of Engineering and Technology (IJET), pp.1601-1614, 2014.

[2] Paul Acarnley, Watson J., Review of position-sensorless operation of brushless permanent magnet machines, in IEEE Transactions on Industrial Electronics, vol. 53, no. 2, pp: 352-362, 2006

[3] Gamazo Real, José Carlos, Ernesto Vázquez Sánchez, Jaime Gómez Gil, Position and Speed Control of Brushless DC Motors Using Sensorless Techniques and Application Trends, Sensors (Basel, Switzerland) $10.7,2010$.

[4] Suneetha, R.Srinivasan, Ramsagar, Co-simulation of BLDC motor commutation by using MATLAB/Simulink and Xilinx System Generator, International Journal of Engineering and Technology (IJET), pp.899-905,2016.

[5] Bojoi R., Pastorelli M., Bottomley J., Giangrande P., Gerada C., Sensorless control of PM motor drives - A technology status review, Electrical Machines Design Control and Diagnosis (WEMDCD), 2013 IEEE Workshop on, Paris, , pp: 168-182 (2013). 
[6] Deenadayalan, A., Saravana Ilango G., Modified sliding mode observer for position and speed estimations in brushless DC motor, In 2011 Annual IEEE India Conference, pp: 1-4,2011.

[7] Hao, Lei, Toliyat., BLDC motor full-speed operation using hybrid sliding mode observer, In Applied Power Electronics Conference and Exposition, Eighteenth Annual IEEE, vol. 1, pp: 286-293,2003.

[8] Fakham, Hicham, Mohamed Djemai, Krishna Busawon, Design and practical implementation of a back-EMF sliding-mode observer for a brushless DC motor, IET Electric Power Applications 2, no. 6, pp: 353-361 ,2008.

[9] Jianbo, Chu, Hu Yuwen, Huang Wenxin, Wang Mingjin, Yang Jianfei, Shi Yuxia, An improved sliding mode observer for position sensorless vector control drive of PMSM, In Power Electronics and Motion Control Conference, IEEE 6th International, pp: 18981902,2009 .

[10] Lee, Hyun, Jangmyung Lee, Design of iterative sliding mode observer for sensorless PMSM control, IEEE Transactions on control systems technology 21, no. 4, pp: 1394-1399, 2013.

[11] Satish Kumar Gudey, Rajesh Gupta, Reduced state feedback sliding-mode current control for voltage source inverter-based higherorder circuit, IET Power Electronics, Vol. 8, Iss. 8, pp: 1367-1376, 2015.

[12] Satish Kumar Gudey, Rajesh Gupta, Second order sliding mode control for a single phase voltage source inverter, In TENCON 20142014 IEEE Region 10 Conference, pp: 1-6. ,2014.

[13] Damiano, Alfonso, Gianluca L. Gatto, Ignazio Marongiu, Alessandro Pisano, Second-order sliding-mode control of DC drives, IEEE Transactions on Industrial Electronics 51, no. 2, pp: 364-373,2004.

[14] Xiaojuan, Yan, Liu Jinglin, A novel sliding mode control for BLDC motor network control system, In 2010 3rd International Conference on Advanced Computer Theory and Engineering (ICACTE), vol. 2, pp: V2-289,2010.

[15] Wang, Yaonan, Xizheng Zhang, Xiaofang Yuan, Guorong Liu, Position-sensorless hybrid sliding-mode control of electric vehicles with brushless DC motor, IEEE transactions on vehicular technology 60, no. 2, pp: 421-432,2011.

[16] Jeon, Jonghyun, Sanggun Na, Hoon Heo, Cascade Sliding Mode-New Robust PID control for BLDC motor of In-wheel system, In Environment and Electrical Engineering (EEEIC), 10th International Conference on, pp: 1-4,2011.

[17] Stînean, Alexandra Iulia, Stefan Preitl, Radu Emil Precup, Emil Petriu, Claudia Adina Dragoş, Mircea Bogdan Rădac, 2-DOF PI (D) Takagi-Sugeno and sliding mode controllers for BLDC drives, In Power Electronics and Motion Control Conference (EPE/PEMC), 2012 15th International, pp: DS2a-7, 2012.

[18] Quintero Manríquez, Eduardo, Ramón Félix, Second-order sliding mode speed controller with anti-windup for BLDC motors, In 2014 World Automation Congress (WAC), pp: 610-615,2014.

[19] Shao, Yunbin, Rongrong Yang, Jianwen Guo, Yongling Fu, Sliding mode speed control for brushless DC motor based on sliding mode torque observer, In Information and Automation, IEEE International Conference on, pp: 2466-2470 ,2015.

[20] Fang, Shipeng, Changhua Hu, Xiaoxiang Hu, Hongzeng Li, Adaptive robust control of brushless DC (BLDC) motor based on sliding mode control (SMC) with unidirectional auxiliary surfaces, In Chinese Automation Congress (CAC), 2015, pp: 1565-1570,2015.

[21] Qingchao, Zhang, Ma Ruiqing, Deng Junjun, Zhao Ben, A cascade first and second order sliding mode control approach for speed control of brushless DC motor, In Control Conference (CCC), 2015 34th Chinese, pp: 3319-3326, 2015.

[22] Satish Kumar Gudey, Rajesh Gupta, Sliding-mode control in voltage source inverter-based higher-order circuits, International Journal of Electronics 102, no. 4, pp: 668-689, 2015.

\section{AUTHOR PROFILE}

Devendra Potnuru is currently working as Associate Professor in department of EEE, GMR Institute of Technology (GMRIT), Rajam. Chennai .He has around 15 years of teaching experience. His areas of current interests are sensorless speed control, Energy conservation, Energy efficient drives and control systems.

Y Santosh Kumar is Post Graduate (M.Tech) student of EEE department, GMRIT, Srikakulam, A.P., India and His areas of current interests are sensorless speed control of BLDC motor and Adaptive control systems. 